\title{
Pregnancy related sickness absence in a Swedish county, 1985-87
}

Kristina Alexanderson, Gunnel Hensing, Margareta Leijon, Ingemar Åkerlind, Hillevi Rydh, John Carstensen, Per Bjurulf

\begin{abstract}
Sickness absence during pregnancy has increased in Sweden as well as in other countries.

Study objective - The study aimed to describe pregnancy related sickness absence and its increase from 1985-87; to consider if the increase were parallel to an increase in sickness absence for all diagnoses or could be explained by a higher birth rate; and to compare different ways of presenting sickness absence data.

Design - The data from a prospective incidence study of all new sick leave spells exceeding seven days in 1985-87 were related to the population at risk through relevant data from different registers.
\end{abstract}

Setting - The county of Östergötland, Sweden (about 400000 inhabitants).

Participants - Subjects were approximately 70000 sick leave-insured women aged 16-44 years, of whom some 15000 had sickness absences > seven days. Some 4600 women gave birth in 1985 , approximately 1300 of whom were listed as having pregnancy related diagnoses. Main results - The number of women with sick leave associated with pregnancy related diagnoses increased by $24 \%(95 \%$ confidence interval (CI) $15,33 \%$ ) during the period. This diagnosis group was one of the very few with an increasing number of people listed as sick. The corresponding increase for all diagnoses in women aged $16-44$ years was $<1 \%(95 \%$ CI 1, 3\%). The increase in the number of women who gave birth was $9 \%(95 \%$ CI 5 , $13 \%)$. The sick leave rate associated with pregnancy related disorders increased by $14 \%(95 \%$ CI $7,21 \%)$ in $1985-87$, while that in all women aged 16-44 years increased by $3 \%(95 \% 1,5 \%)$. $(p<0.0001)$. The number of sick leave days associated with pregnancy related disorders increased by $49 \%(p<0.0001)$ in the period - twice the equivalent increase $(p<0.0001)$ in the total number of sick leave days for all diagnoses taken together. The sick leave rate and duration, like the increase in these variables, varied with age. Different ways of presenting the length of absence proved complementary to each other.

Conclusions - After correcting for changes in the overall sick leave rate and in the birth rate, there is still an $11 \%$ increase in the sick leave rate associated with pregnancy related disorders that needs to be explained. Medical factors cannot explain this increase but changes in attitudes and practice in relation to sickness insurance among pregnant women and their doctors merit further study.

\section{( $\mathcal{F}$ Epidemiol Community Health 1994;48:464-470)}

Pregnancy is not a disease, but sickness absence during pregnancy has increased in Sweden $^{1}$ as well as in other countries ${ }^{2-4}$ and more knowledge is needed about the epidemiology of this special phenomenon.

The female employment rate has grown in the industrialised world and more women tend to work both during pregnancy and for longer into pregnancy than previously. ${ }^{56}$ Although there are several studies on the effects of employment, education, social status, social network, etc on pregnancy outcome, ${ }^{46-9}$ only a few examine how these factors are related to the pregnant woman's health, ${ }^{10-14}$ and there is little knowledge of how this is reflected in sickness absence during pregnancy.

This study aimed to:

(1) Describe pregnancy related sickness absence and its increase from 1985-87, overall and in related to age.

(2) Analyse possible causes of the increase in pregnancy related diagnoses focussing on two hypotheses as follows: (a) Was the increase parallel to an increase in sickness absence in all diagnoses? (b) Was it due to the baby boom that began in Sweden during this period?

(3) Compare different ways of presenting the number of absence days/person.

\section{Methods}

SICK LEAVE REGISTRATION PROJECT OF ÖSTERGÖTLAND

The study is based on material from a total incidence study in the Sick-Leave Registration Project of Ostergötland. ${ }^{15}$ The core of the project is a register including all new sick leave spells exceeding seven days, for each of the years 1985, 1986, and 1987 in the county of Östergötland, Sweden. With each spell, a number of demographic variables were registered, including sex, age, and diagnosis. ${ }^{16}$ Each spell was followed until its end or, at the longest, until September 1 the following year. There was a $15 \%$ "drop out" in recording the spells in 1985 and 1987 and a $12 \%$ rate in 1986. We did not find any association between "drop out" and variables of interest in this study. ${ }^{15}$ 
The project was approved of by the ethical committee of the medical faculty of Linköping as well as by the Swedish Data Inspection Board.

In Sweden, self certification is accepted for the first seven days of illness, and to increase the validity of the diagnoses, these shorter spells of sick leave were excluded. Although the spells of self certified sick leave are many in number, they constitute only a small part of the total number of sick absence days. ${ }^{15}$

The agreement between the diagnoses and their coding has been tested elsewhere, and has proved to be acceptable. ${ }^{17}$

Some 45000 people of all ages were insurance registered, and had about 61000 spells of sick leave during each of the years 1985, 1986, and 1987. This means that both the number of people with sick leave spells exceeding seven days, and of the spells themselves, were fairly stable over the years. However, the number of sick leave days increased. ${ }^{15}$

\section{PREGNANCY RELATED DIAGNOSES}

From the above mentioned register and for each of the three years, data on all women aged 16-44 years who were listed as being absent with pregnancy related diagnoses have been extracted. This means all diagnoses where it was possible to conclude from the sickness certificate that the woman was pregnant - that is, diagnosis numbers, according to NOMESCO ${ }^{16} 634 R, 635$, and 637: toxichoses, bleeding, urinary tract infections during pregnancy, abortion, early labour, and also backache and fatigue due to pregnancy. The register does not otherwise state if a woman is pregnant.

As shorter spells are excluded, most women have only one spell per year. The focus of the study will be on women who were sick listed and on the length of their sick absence, not on spells.

In order to analyse whether the increase in pregnancy related sickness absence is parallel to a similar increase in all diagnoses, data from the register of the total sickness absence among women aged 16-44 was used.

In order to relate our data to the population at risk, we have used relevant data for women aged 16-44 from two different sources:

(1) Data from the local insurance office of the number of all sick leave-insured people during the three years.

(2) The Medical Birth Register ${ }^{18}$ of 1985 , 1986 , and 1987, to obtain data on all women who gave birth.

In 1985, the county of Östergötland had nearly 400000 inhabitants $-5 \%$ of Sweden's total population. Östergötland, located in the south east of Sweden, is an expanding, highly industrialised area with both urban and rural municipalities. The county can be considered representative of at least southern Sweden, where $85 \%$ of the population lives. ${ }^{19}$

SICKNESS INSURANCE, MATERNITY AND

PARENTAL LEAVE IN SWEDEN

Nearly all Swedish residents aged 16-65 (including the self employed, housewives, students, and unemployed seeking work) are covered by a national sickness insurance. Sickness absence covers work incapacity through disease, injury, or illness, not confinement, maternity, or parental leave. There is no maximum duration of a sick leave spell in Sweden.

Swedish law grants women who have a child parental leave from work for $1 \frac{1}{2}$ years, with the right to return to the same or similar tasks after such leave. Parental benefit is granted for 280 days, of which 60 days can be used before the expected date of birth. If modified working conditions cannot be arranged for a pregnant woman whose work is strenuous, she can receive precautionary maternity leave from the 60 th to the 10th day before the expected date of birth.

During the years studied, sickness, maternity, and parental benefits amounted to at least $90 \%$ of lost income.

\section{STATISTICS}

The term "sick leave rate" refers to the proportion of women, within each group, who have had one or more sick leave spells exceeding seven days during a year.

Normal approximation tests have been used for differences in rates between years and groups, and the $t$ test for mean differences. ${ }^{20}$ Differences in counts were tested using the Poisson assumption. ${ }^{21}$ Comparisons in all tables were made under the assumption that the groups can be considered as independent samples, so the sampling error is probably slightly overestimated.

\section{Results}

The number of women sick listed for pregnancy related diagnoses increased by $24 \%$ between 1985 and 1987 (table 1). There was no equivalent change for "all diagnoses". This was one of the very few diagnostic groups that showed an increase in the number of sick listed people. The other main group, which showed an increase of $22 \%$, comprised diagnoses related to musculoskeletal problems. This and the results that follow are in women aged 16-44 years only.

Between 1985 and 1987, the number of women who delivered rose by $9 \%$. Of the women giving birth in 1985, $29 \%$ were below 25 years of age and $60 \%$ in the age group 25-34 years. This ratio did not change appreciably till 1987.

\section{SICK LEAVE RATE}

Among all pregnant women, the sick leave rate for pregnancy related diagnoses was 0.29 in 1985. In all sick listed women with all diagnoses, it was $0.22(p<0.0001)$. In figure 1 these rates are separated into three age groups. The rate increased with age $(p<0.001)$ for pregnancy related diagnoses.

From 1985-87, the sick leave rate of women with pregnancy related diagnoses increased by $13.6 \%(95 \%$ confidence interval (CI) 6.9, 
Table 1 Women aged 16-44 years in the county of Östergötland who were insured for sick leave, listed as having taken sick leave*, and gave birth during the years 1985-87

\begin{tabular}{|c|c|c|c|c|c|c|}
\hline & \multirow[b]{2}{*}{$\begin{array}{l}1985 \\
\text { No }\end{array}$} & \multirow[b]{2}{*}{$\begin{array}{l}1986 \\
\text { No }\end{array}$} & \multirow[b]{2}{*}{$\begin{array}{l}1987 \\
\text { No }\end{array}$} & \multicolumn{3}{|c|}{ Increase $1985-87$} \\
\hline & & & & $\%$ & $95 \% C I$ & p value \\
\hline $\begin{array}{l}\text { Listed as sick with } \\
\text { pregnancy related } \\
\text { diagnosis }\end{array}$ & 1302 & 1568 & 1612 & 24 & 15,33 & $0 \cdot 0001$ \\
\hline Gave birth & 4564 & 4829 & 4972 & 9 & 5,13 & $0 \cdot 0001$ \\
\hline $\begin{array}{l}\text { Listed as sick } \\
\text { (all causes) }\end{array}$ & 15358 & 15482 & 15498 & 1 & $-1,3$ & 0.5 \\
\hline $\begin{array}{l}\text { Insured for sick } \\
\text { leave }\end{array}$ & 69835 & 68668 & 69037 & 0 & $-2,0$ & $0 \cdot 02$ \\
\hline
\end{tabular}

* Only spell of sick leave longer than seven days were included.

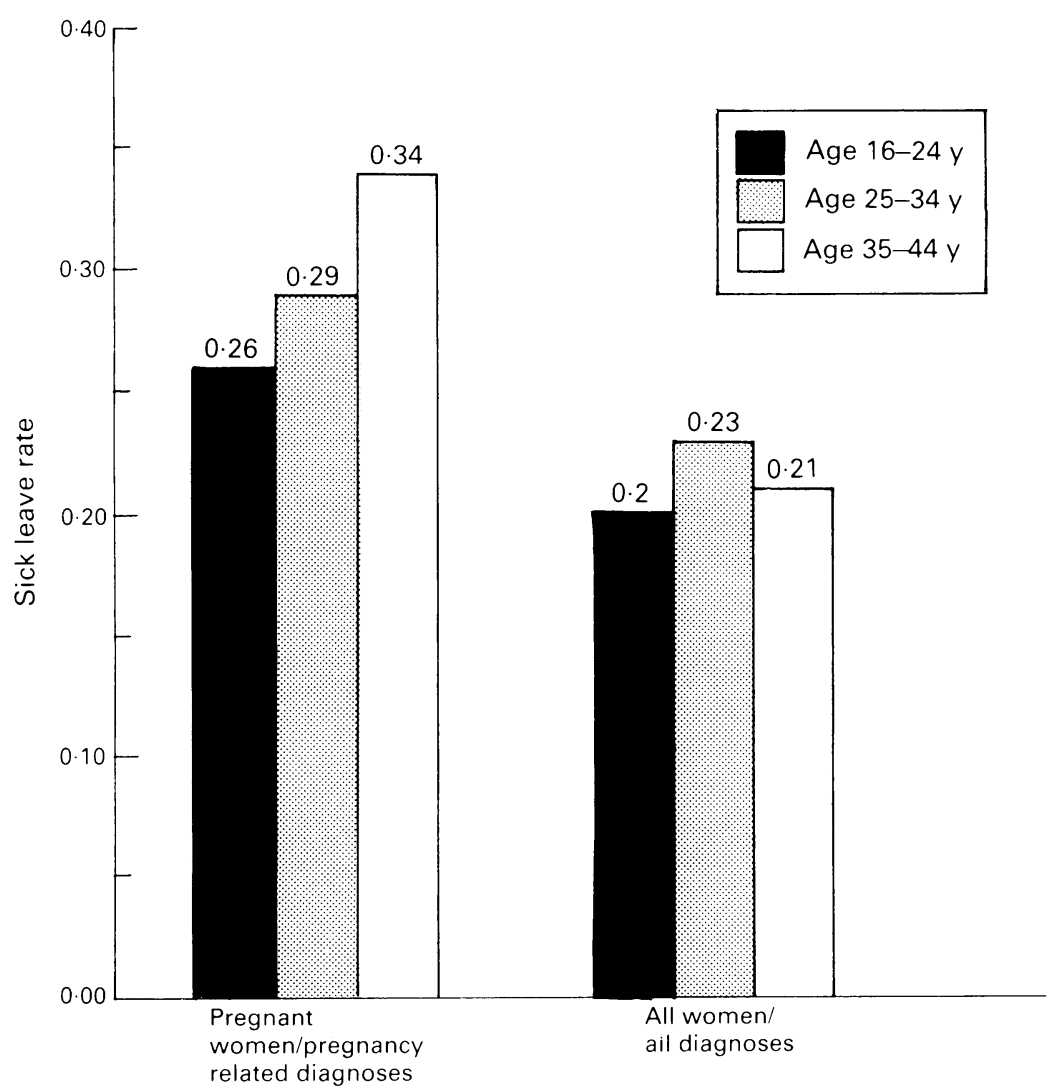

Figure 1 Sick leave rate for women with pregnancy related diagnoses and all sick leave insured women for all diagnoses in 1985. Note: rate equals the number of women in the group that had at least one sick leave spell $>7$ days divided by the number of women in the group.
$20 \cdot 8 \%)$. This change was significantly higher $(\mathrm{p}<0.0001)$ than the increase in the sick leave rate of all women aged 16-44 in all diagnoses; $2.7 \%(95 \%$ CI $0.7,4.7 \%)$. The increase was highest among the youngest group of pregnant women, although the difference was not statistically significant (fig 2 ).

SICKNESS ABSENCE DAYS

Women aged 16-44 years had a total of c 710000 sickness absence days in 1985. In 1987 , this number had increased by $23 \%$ $(\mathrm{p}<0.0001)$. The sickness absence days for pregnancy related diagnoses were c 52000 in 1985 and this number had increased more than two fold in 1987 to $49 \%$ for women 16-44 years $(p<0.0001)$ and to $69 \%$ for women below 25 years $(\mathrm{p}<0.0001)$.

This higher increase is mainly a result of more women being sick listed for pregnancy related diagnoses not of a higher increase in leave duration per woman sick listed for pregnancy related diagnoses than for all diagnoses. The number of sickness absence days per absent woman for pregnancy related diagnoses increased by c $20 \%$ from $1985-87$, as did the number of days for all diagnoses among all sick listed women. However, it differed with age (table 2).

In table 3 , the mean number of absence days per sick leave insured women is shown. The increase in pregnancy related diagnoses was more than twice that in all diagnoses $(\mathrm{p}<0.0001)$. In addition, sick absence days associated with pregnancy related diagnoses can be related to all pregnant women, as in table 4 . The increase in days was highest in the youngest and oldest age groups.

Tables 2 and 4 show that women aged $35-44$ years were absent with pregnancy related diagnoses for longer periods than the younger women. The fewer sick absence days per woman with a pregnancy related diagnosis in the older women in table 3 can be explained by the low birth rate in this group.

\section{Discussion}

Sickness absence has been seen as related to

Table 2 Number of sickess absence days* per woman listed as sick and the number of sickness absence days associated with pregnancy related diagnoses per sick listed pregnant woman in Östergötland 1985 and 1987

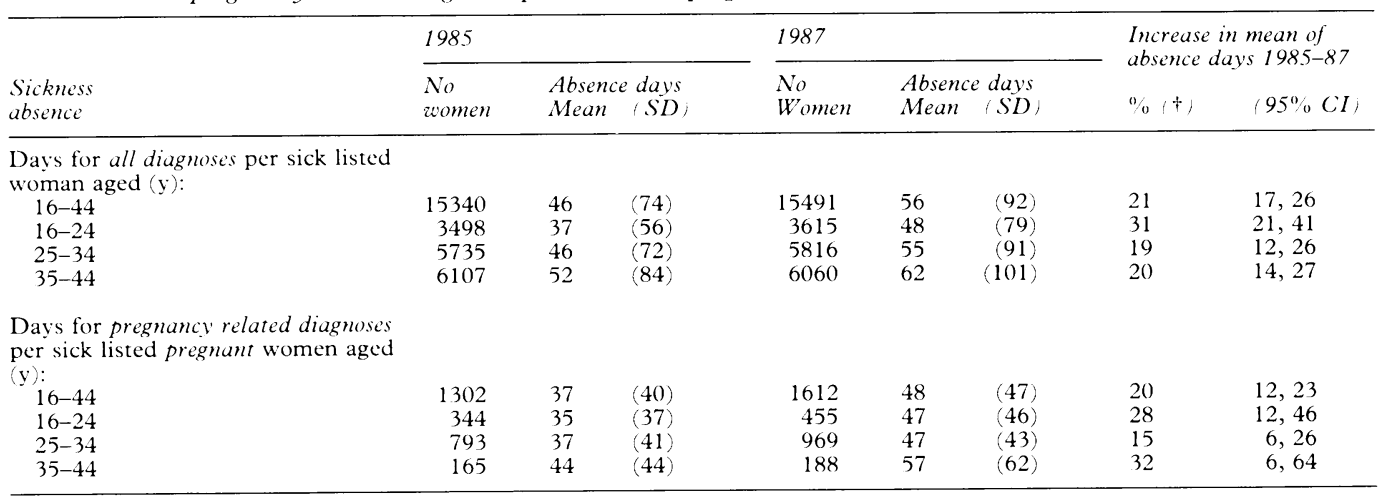

* Only sick leave spells exceeding seven days were included.

The $\%$ change is significant, with $\mathrm{p}<0.00001$ in all age groups except the following: pregnant women aged $25-34$ years, $\mathrm{p}<0.001$ and pregnant woman aged $35-44$ years, $\mathrm{p}<0.016$. 
Table 3 Sickness absence* days per sick leave insured woman for all diagnoses and for pregnancy related diagnoses in Ostergötland in 1985 and 1987

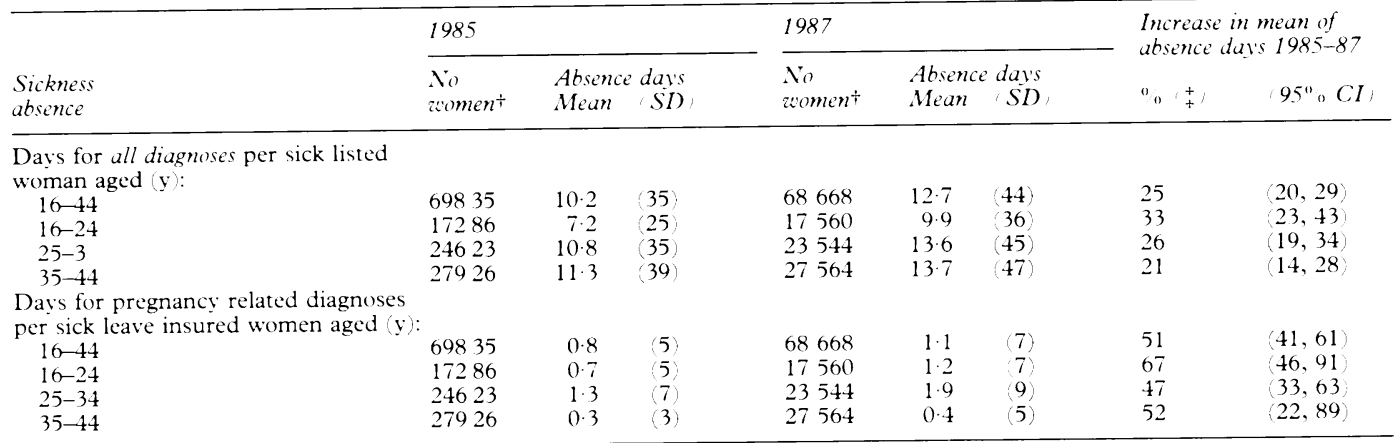

* Only sick leave spells exceeding seven days were included.

+ No of women that are sick leave insured on December 31 , each year, according to the National Insurance Office.

* The ${ }^{\circ}{ }_{n}$ change is significant, at $\mathrm{p}<0.0001$ in all age groups.

Table 4 Sickness absence day* for pregnancy related diagnoses per pregnant woman† in Östergötland in 1985 and 1987

\begin{tabular}{|c|c|c|c|c|c|c|c|c|}
\hline \multirow[b]{2}{*}{$\begin{array}{l}\text { Age } \\
\text { group y }\end{array}$} & \multicolumn{3}{|l|}{1985} & \multicolumn{3}{|l|}{1987} & \multicolumn{2}{|c|}{$\begin{array}{l}\text { Increase in mean of } \\
\text { absence days } 1985-87\end{array}$} \\
\hline & $\begin{array}{l}\text { No } \\
\text { zoment }\end{array}$ & $\begin{array}{l}\text { Absen } \\
\text { Mean }\end{array}$ & $\begin{array}{l}\text { days } \\
\text { SiD }\end{array}$ & $\begin{array}{l}\text { No } \\
\text { woment }\end{array}$ & $\begin{array}{l}\text { Absenc } \\
\text { Mean }\end{array}$ & $\begin{array}{l}\text { days } \\
S D\end{array}$ & $n_{0}+$ & $95^{\circ}, C I$ \\
\hline $16-44$ & 4564 & 11 & (20) & 4972 & 16 & (27) & 37 & $(28,47)$ \\
\hline $16-24$ & 1330 & 10 & 26 & 1476 & 14 & 25 & 52 & $(33,74$ \\
\hline $25-34$ & 2747 & 12 & (20) & 3007 & 15 & (25) & 29 & $(18,40)$ \\
\hline $35-44$ & 487 & 15 & (18) & 489 & 22 & (39) & 49 & $(20,86)$ \\
\hline
\end{tabular}

* Only sick leave spells exceeding seven days included.

\pm The ${ }^{\circ}$ change is significant, with $\mathrm{p}<0.0001$ in all the age groups.

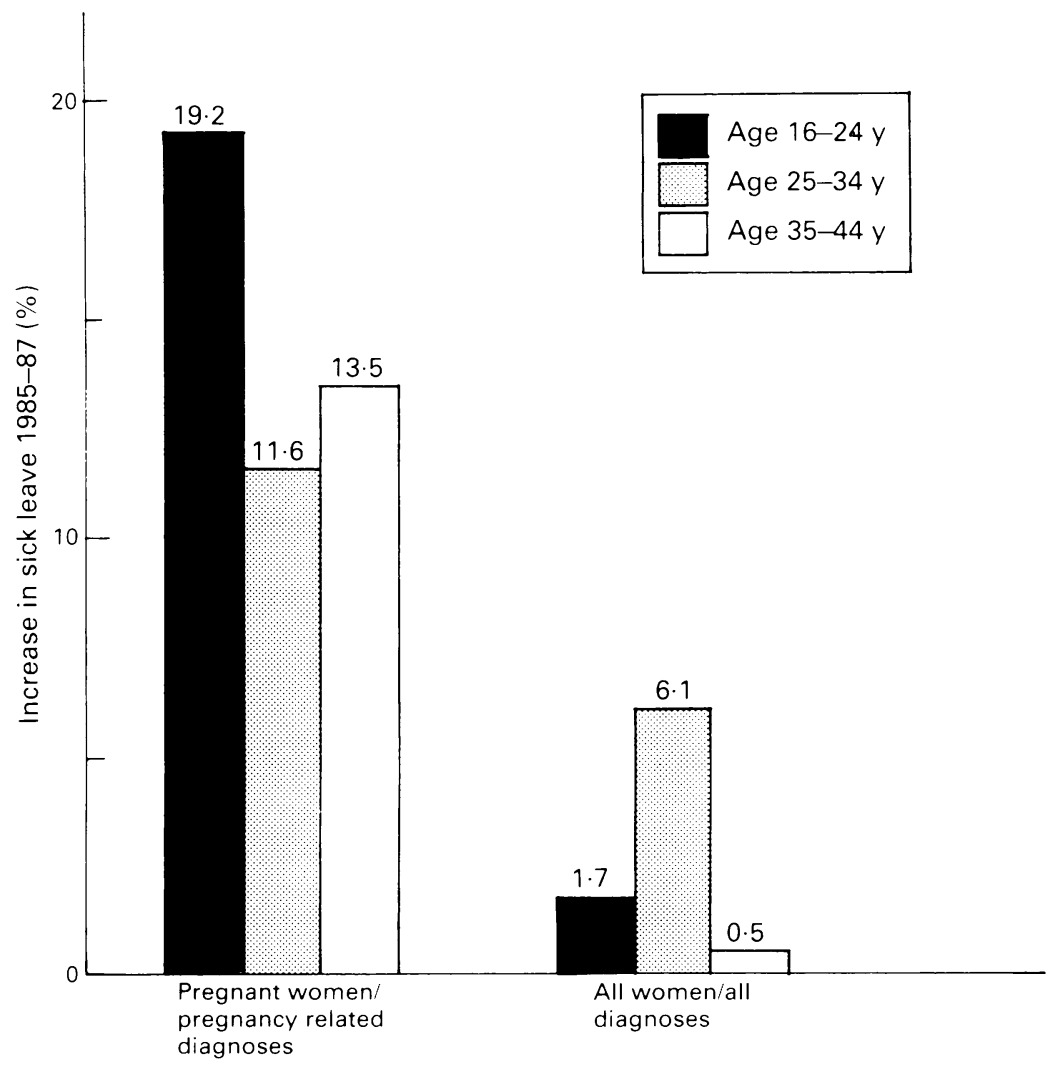

Figure 2 Percentage increase in the sick leave rate see legend 5 fig 1, between 1985 and 1987 in women with pregnancy related diagnoses and all women for all diagnoses. one or more of the following - work demands, malingering, a coping strategy, or effects of changes in the structure of the work force. ${ }^{22}$ With regard to the recent increase in sick listing during pregnancy, there are additional hypotheses, for example, is it due to increased morbidity, a higher birth rate, or a general change of attitudes among pregnant women or their doctors. ${ }^{1352324}$

In Sweden, the years 1985-87 were characterised by a growing birth rate, a very low unemployment rate, and increasing sickness absence. However, sickness absence increased only in relation to a few diagnoses,,$^{25}$ including pregnancy related diagnoses.

We investigated the incidence and trends in pregnancy related sickness absence between 1985 and 1987 in a large, well defined population. Many studies in this area are based on self reported data from questionnaires. The data in this study, based on the official register, can be considered to be more valid. To protect personal integrity, registers of sickness absence in Sweden can not normally include the diagnosis, as in many western countries, which makes our register unique in some respects.

This study covers sickness absence exceeding seven days for pregnancy related diagnoses, not short absences or absences with other diagnoses during pregnancy or maternal or parental leave. Our results do not give a total picture of sick leave during pregnancy, but do provide information to add to the still fragmentary knowledge on this subject. Some clear tendencies can be seen, such as a con- 
siderable increase in both the number of sick listed women with pregnancy related diagnoses, especially younger women, and in the length of pregnancy related sick leave from 1985-87.

Comparisons with other studies are not easy because of large variations in study designs, different national social security systems, ${ }^{2627}$ and variations in the female employment rate. Our sick leave rates were lower than those in other studies. ${ }^{23232832}$ One reason for this could be that our study does not include all spells of illness during pregnancy. We only found one study - of a selected group of pregnant Norwegian women ${ }^{33}-$ with a lower rate. In fact, this is the oldest (1979-81) study we found, and it might have been completed before the increase in pregnancy related sickness absence begun. Lundby ${ }^{28}$ found a sick leave rates of 0.51 for all spells and 0.29 for spells $>14$ days. The 14 day cut off point in this study makes comparisons with our material difficult.

INCREASE IN WOMEN SICK LISTED WITH PREGNANCY RELATED DIAGNOSES

The increases in women sick listed with pregnancy related diagnoses and in the sick leave rate were large - parallel to, but much higher than, findings in other studies. ${ }^{13}$ Most studies of sickness absence during pregnancy cover shorter periods than ours or do not study changes over time. However, when comparing different studies ${ }^{1-42328313435}$ it is evident that the sick leave rate for pregnant women has increased over time in France, Norway, Denmark, and Sweden.

Thirty eight per cent of the increase we found could be explained by a higher birth rate. The increase in pregnancy related diagnoses was even higher than that for musculoskeletal diagnoses. After correction for birth rate, there is still an unexplained $11 \%$ increase in the sick leave rate in these diagnoses.

From different studies ${ }^{101436}$ one can conclude that physically heavy jobs, low social support, age, immigrant status, and poverty often go together with bad health in pregnancy. However, none of these factors has changed dramatically, if at all, in Östergötland during the years of the study. Furthermore, no parallel increase in workplace related risk factors or in morbidity during pregnancy has been reported for the three years, so medical explanations for the remaining $11 \%$ are not plausible.

The number of women who give birth is not exactly the same as the number of pregnant women, which means that some women who did not give birth might have been sick listed for pregnancy related diagnoses. However, there is no register of pregnant women in Sweden. The difference here can be considered negligible as maternity mortality in Sweden is practically zero and late miscarriages few. There were no changes between 1985 and 1987 in the number of miscarriages, multiple pregnancies, etc.
INCREASE IN PREGNANCY RELATED SICKNESS ABSENCE DAYS

The increase in the number of sickness absence days associated with pregnancy related diagnoses was substantial, something that has not been studied elsewhere. However, in existing cross sectional studies there is a trend towards more sickness absence days during pregnancy the more recently the studies have been done. ${ }^{1-323}$

Sickness absence studies focus mainly on the frequency of absences or the length of these, or both. ${ }^{37}$ Length is often presented as the mean number of absence days per person, but different nominators are used in different studies, which not only makes comparisons between studies difficult, but also has consequences for the interpretation of results. Nominators used are usually either all sick listed or the total population at risk. In order to compare them, we have used both these ways, and defined the population at risk of sickness absence in two different ways: all sick leave insured women and all women that gave birth.

These three different ways of presenting length of absence give somewhat divergent results concerning length, increase of length, and when comparing the increase in length for pregnancy related diagnoses with that in all diagnoses. How is this to be interpreted?

Firstly, the number of absence days per sick listed woman in both groups (pregnancy related diagnoses and all diagnoses together) increased equally by $20 \%$, thus the increase in pregnancy related absence days could be explained by a general tendency of sick listed women of these ages to take longer sick leave.

Relating the number of absence days to the risk population gives a picture of how sickness absence is distributed in the population. This is often used to illustrate the trend in sickness absence over time, or differences between subgroups (for example, according to sex, age, immigrant status, etc). ${ }^{38}$ Using this method when studying separate diagnoses is trickier. The results are related, for example, to the incidence and prevalence in the one diagnosis and to the incidence and prevalence in other diagnoses. If a person is already sick listed for one diagnosis, she cannot be sick listed for another at the same time. With pregnancy related diagnoses, the birth rate of the population also has to be considered.

When using the second method, the number of sick leave insured women as the risk population, the length of absence with pregnancy related diagnoses increased more than the length for all diagnoses together during the three years. This is mainly because of the increased birth rate.

The third method, using all women giving birth as the risk population, seems the most relevant. However, one has to consider that a very small proportion of these women may not be sick leave insured because they have a full disability pension. The increase we found in the length of leave with pregnancy related diagnoses is higher when using sick leave insured women than when using pregnant women as the risk population, because the 
number of sick leave insured women fell, while the number of pregnant women increased.

Obviously, the different ways of presenting the length of absence give different pictures that can be complementary to each other. In this study, the number of absence days per person is mainly used to compare the increase in pregnancy related diagnoses with the increase in all diagnoses. If we wanted to compare the length of absence (not the increase in length) between the groups instead, we would have to take into account the different risk periods. The time during a year that a women is at risk of pregnancy related sick listing is shorter than the time she is at risk of being sick listed for other diagnoses. It is difficult to say how long the "risk time" actually is for pregnancy related diagnoses. Although nine months may be correct in theory, it certainly is not in practice. When studying absence length (not increase of length) pregnancy related diagnoses days per insured subject is somewhat misleading because birth rates vary with age. Tables 2 and 4 are complementary to each other here; in both, the length of absence increased with age.

\section{AGE VARIATIONS}

We have only found two studies ${ }^{328}$ that report differences in the sick leave rate during pregnancy in relation to age, but none that investigated how duration varies with age. In contrast to our results, Grünfeldt ${ }^{3}$ found no difference regarding age between pregnant women who were and were not sick listed. In age groups corresponding to ours, Lundby ${ }^{28}$ reports sick leave rates of $0.58,0.48$, and 0.60 respectively for employed pregnant women. Their higher rates are to be expected as they include both all diagnoses and the shorter spells. Their rates are, like ours, higher among older women.

The high sick leave rate of the older pregnant women is not surprising. Women over 35 are more closely monitored due to the higher risk of prenatal and perinatal complications. Furthermore, more of them have previous children, leading to a higher work load when the impact of paid and unpaid work is combined. ${ }^{1123333539}$ Age itself often makes pregnancy harder. This might contribute not only to the higher rates, but also to the longer absences in these age groups. However, it does not explain the increase, and especially not the higher increase, in sick leave rates among the younger women. We found an increase in both incidence and length of absence at all ages but this increase was highest among women under 25 years of age. From a medical perspective, the opposite could be expected.

\section{ConClusions}

Between 1985 and 1987 we found an $11 \%$ higher increase in the sick leave rate for pregnancy related diagnoses than for all diagnoses in sick listed women aged 16-44 years. The number of sickness absence days also increased, to some extent parallel to a similar increase among all sick listed women aged $16-44$ years in all diagnoses.
There are no medical explanations for the increase. Some of it can be accounted for by two verdicts in the social insurance court of appeal which somewhat increased the range of conditions for which pregnant women could be sickness certified. The main explanation might be a change of attitudes of pregnant women or the doctors who certify their sick leave.

During pregnancy and after delivery, a woman goes through one of the most profound changes in her life. She experiences sweeping changes in her physical well-being, emotional state, and social relationships. Common reactions are backache, sleep disturbances, fatigue, nausea, pain in legs and feet, appetite disturbances, etc. ${ }^{3640-43}$

In a world wide, cross cultural study of 202 traditional societies, it was found that in most the workload on women during pregnancy was lightened. ${ }^{44}$ Maybe women today are redefining their role in the contemporary industrial world.

Few employed women today work until delivery. ${ }^{40}$ Most women now use sick leave instead of maternity/parental leave for this absence. ${ }^{1}$ This might be due to a change of attitudes or coping strategies. ${ }^{45}$ If a woman uses parental leave for this purpose, she will have a shorter "paid" leave after delivery. At a time when most women continue to work after giving birth, it seems like a better coping strategy to use sick leave instead of parental leave before delivery. Thus, the pregnant woman presents all possible complaints to convince her doctor that she should be sick listed, a situation that often has a negative effect on the atmosphere in the consulting room. To address this situation, earmarked "pregnancy leave" weeks, which each pregnant women could choose to use before delivery, has been suggested. ${ }^{330}$

In public health studies, sickness absence is often used as indicator of morbidity, combined with self reported illness and diagnosed disease. This study indicates that extra caution is to be recommended when using sickness absence in pregnancy as data for morbidity.

This study was supported by the Swedish Council for Planning and Coordination of Research and by the Swedish Medical Research Council.

1 Lindmark G. Kvinnors behov av ledighet under graviditet borde tillgodoses utan att klassas som sjukdom (Women's need of absence during pregnancy should be met without being classified as disease) (In Swedish). Läkartidningen 1992;89(21):1882-84

2 Mamelle N, Bertucat I, Munoz F. Pregnant women at work: rest periods to prevent preterm birth. Paediatric and Perinatal Epidemiology 1989;3:19-28.

3 Grünfeld B, Qvigstad E, Sykdom under svangerskapet (Sick leave among pregnant women in Oslo) (In Norwegian). Tidsskr Nor Lageforen 1991;111(10):1269-72.

4 Saurel-Cubizolles MJ, Subtil D, Kaminski M. Is preterm delivery still related to physical working conditions in pregnancy? $\mathcal{f}$ Epidemiol Community Health 1991;45:29preg.

5 Chamberlain G. Women at Work in Pregnancy. In: Chamerlain G, ed. Pregnant Women at Work. London:
The Royal Society of Medicine, 1984.

6 Saurel-Cubizolles MJ, Kaminski M. Work in pregnancy: its evolving relationship with perinatal outcome (A review). evolving relationship with perinat
Soc Sci Med 1986;22(4):431-42.

7 Nurminen T, Kurppa K. Office employment, work with video display terminals and course of pregnancy. Scand $\mathcal{F}$ Work Environ Health 1988;14:293-8. 8 Marbury MC. Work and pregnancy. $f$ Occup Med
$1984 ; 26(6): 415-21$. 
9 McDonald AD, McDonald JC, Armstrong B, et al. Occupation and pregnancy outcome. Br f Ind Med 1987;44:521-6. 10 Hall M. Health of pregnant women. BMF 1991; 303(24):460 2.

11 Røssaak E, Jacobsen G. Helseforhold blant gravide. (State of health among pregnant) (In Norwegian). Tidsskr Nor Lageforen 1987;107(17-18):1578-9.

12 Gjerdingen KD, Froberg GD, Kochevar L. Changes in women's mental and physical health from pregnancy
through six months postpartum. $f$ Fam Pract 1991;32(2):161-6.

13 O'Hara MW. Social support, Life events and depression during pregnancy and the puerperium. Arch Gen Psychiatry 1986;43:569-73.

14 Brown MA. Employment during pregnancy: influences on women's health and social support. In: Women's work, families, and health. Washington: Hemisphere Publishing Corporation, 1987: 151-167.

15 Alexanderson K, Leijon M, Àkerlind I, Rydh H, Bjurulf $\mathrm{P}$ Epidemiology of sickness absence in a Swedish county in 1985, 1986, and 1987. Scand F Soc Med 1994;22(1):27-34.

16 Nordic Medical Statistical Committee. Code-list for diagnose used in ambulatory care. Stockholm: Nordic Medical Statistical Committee, 1976

17 Ljungdahl L, Bjurulf $\mathrm{P}$. The accordance of diagnoses in a computerized sick-leave register with doctor's certificates and medical records. Scand F Soc Med 1991;19(3):148-53.

18 Medicinsk födelseregistrering (Medical birth registration) Stockholm: Statistics Sweden.

19 Folkhälsorapport för Östergötland 1993 (Public Health in Östergötland, Report 1993) (In Swedish). Linkoping: The County of Östergötland, 1993.

20 Kirkwood B. Essentials of medical statistics. Oxford: Blackwell Scientific Publications, 1988

21 Armitage P, Berry G. Statistical methods in medical research. Oxford: Blackwell Scientific Publications, 1987.

22 Vogel J, Kindlund H, Diderichsen F. Arbetsförhållanden, ohälsa och sjukfranvaro 1975-1989. (Working conditions, illness and sickness absence in 1975-1989) (In Swedish) Stockholm: Statistics Sweden, 1992.

23 Sydsjö A, Sydsjö G, Wijma B. Hög sjukfrånvaro under graviditeten trots väl utbyggt föräldraförsäkringssystem (High sickness absence during pregnancy in spite of well developed parental leave insurance) (In Swedish). Läkartidningen 1989;86(47):4141-44.

24 Birkeland FG. Sykmelding av gravide (Sick-leave during pregnancy) (In Norwegian). Tidsskr Nor Lœegeforen pregnancy) (In No

25 Bjurulf $P$, Johansson G, Ljungdahl L, Persson H, Levin J-E, Âstrand G. Sjukskrivning i förhållande till diagnos och yrk 1985-1987 i Ostergötlands län (Sickness absence in relation to diagnosis and occupation in the county of Östergötland, in 1985 to 1987) (In Swedish). Linköping: Dept of Community Med, 1990.

26 Henrekson M, Lantto K, Persson M. Bruk och missbruk av sjukförsäkringen. (Use and malingering of sickness absence) (In Swedish). Stockholm: SNS förlag, 1992.

27 Prins R, De Graaf A. Comparison of sickness absence in Belgian, German, and Dutch firms. $\mathrm{Br} f$ Ind $\mathrm{Med}$
1986;43:529-36.

28 Lundby IH, Tellness G, Stray-Pedersen B. Graviditet og sykmelding (Pregnancy and sick-leave) (In Norwegian) Tidsskr Nor Lageforen 1988:108(27):2291-4.

29 Lundby IH, Stray-Pedersen B, Tellness G. Diagnoser brukt ved sykmelding av gravide. (Diagnoses among pregnant women certified sick) (In Norwegian). Tidsskr Nor Laegeforen 1991;111(23):2833-6.

30 Saurel-Cubizolles M-J, Romito P, Garcia J. Description of maternity rights for working women in France, Italy and in the United Kingdom. European Fournal of Public Health 1993;3:48-53.

31 Larsson G. Mödrahälsovård i utveckling (Maternity care in development) (In Swedish), Malmö: Utbildningsproduktion $\mathrm{AB}, 1988: 31-64$

32 Saurel-Cubizolles MJ, Kaminski M. Pregnant women's working conditions and their changes during pregnancy: a working conditions and their changes during pregnancy: a

33 Jotion Norway. Scand $\mathcal{f}$ Prim Health Care 1989;7:27-32.

34 Håkansson A. Antenatal care in general practice in Sweden. Scand 7 Prim Health Care 1988;6:137-42.

35 MOR 88. En undersökning av gravida kvinnors sjukskrivning. (An investigation of sickness absence of pregnant women in 1988) (In Swedish). Stockholm: Försäkringskassan, Stockholms län, 1990.

36 Gjerdingen KD, Froberg GD, Fontaine P. The effects of social support on women's health during pregnancy, labor and defivery and the postpartum period. Fam Med 1991;23(5):370-75.

37 Muchinsky P. Employee absenteeism: A review of the literature. Journal of Vocational Behavior 1977;10:316-40.

38 Isacsson A, Hanson B, Janzon L, Kugelberg G. The epidemiology of sick leave in an urban population in Malmö, demiology of scand f Soc Med 1992;20(4):234-39

39 Romito P. Woman's paid and unpaid work during pregnancy. A psycho-social analysis. London: Thomas Coram Research Unit, 1989;1-85.

40 Strand K, Wergeland E, Endresen EH, Bjerkedal T. Factors associated with work status of pregnant employees in Norway 1989. In: Wilma K, Schoultz von B, ed. Advances in research in psychosomatic obstetrics and gynaecology. Carnforth: The Pantheon Publishing Group, $1991 ; 617-623$.

41 Ostgaard HC. Back pain and pregnancy. Göteborg: University of Göteborg, 1991. Doctoral dissertation.

42 Myllynen L. Work during pregnancy. Helsinki: University Central Hospital, Helsinki, Finland, 1991. Doctoral dissertation.

43 Petersen K, Hørding U, Roepstorff C, Kamper-Jørgensen F, Larsen J. Selvrapporteret sygdoms- og indlæggelsemønster under graviditet (Self-reported illness in pregnancy) (In Danish). Ugeskr Lager 1989;151(10):621-5.

44 Jimenez $M H$, Newton N. Activity and work during pregnancy and the postpartum period: A cross-cultural study of 202 societies. Am $\mathcal{f}$ Obstet Gynecol 1979;135(2):171-6.

45 Friberg T. Kvinnors vardag (Everyday life of women) (In Swedish). Lund: University of Lund, 1990. Doctoral dissertation. 